\title{
Localização de zonas de cisalhamento potenciais para o armazenamento do excesso de água pluvial
}

Aline Isabel de Pádua (linepadua@gmail.com - Discente de Geofísica IG/UnB)

Welitom Rodrigues Borges (welitom@unb.br - Docente do Instituto de Geociências/UnB)

Luciano Soares da Cunha (lucianosc@unb.br - Docente do Instituto de Geociências/UnB)

José Eloi Guimarães Campos (eloi@unb.br - Docente do Instituto de Geociências/UnB)

Márcio Maciel Cavalcante (marciom@unb.br - Mestrando do Instituto de Geociências/UnB)

Felipe Sena (fgsena22@gmail.com - Discente de Geologia.IG/UnB)

\section{Copyright 2012, SBGf - Sociedade Brasileira de Geofísica}

Este texto foi preparado para a apresentação no V Simpósio Brasileiro de Geofísica, Salvador, 27 a 29 de novembro de 2012. Seu conteúdo foi revisado pelo Comitê Técnico do V SimBGf, mas não necessariamente representa a opinião da SBGf ou de seus associados. É proibida a reprodução total ou parcial deste material para propósitos comerciais sem prévia autorização da SBGf.

\section{RESUMO}

Este trabalho apresenta os resultados da aplicação do método geofísico de eletrorresistividade na definição de características geométricas de aquíferos fissurais, objetivando a detecção de zonas de cisalhamentos em rochas cristalinas. Onde os principais fraturamentos comportaram-se como zonas de baixa resistividade, devido ao fato de que estas regiões facilitam a percolação das águas, provocando uma maior alteração da rocha. Este dimensionamento permitirá a maximização da estocagem subterrânea do excesso de água pluvial. Os locais escolhidos para a realização dos levantamentos foram assentamentos e comunidades onde é viável o sistema de estocagem da água a partir dos telhados das residências. Os resultados obtidos foram coerentes com o esperado para zonas de cisalhamento.

\section{INTRODUÇÃO}

A escassez de água no Nordeste do Brasil é uma constante preocupação e induz o governo a desenvolver projetos de gerenciamento de recursos hídricos superficiais e subterrâneos na região. Este trabalho visa uma possível alternativa de minimizar a escassez de água no período de estiagem, através do armazenamento subterrâneo do excesso das águas pluviais. Assim meios que viabilizem este estudo são de grande interesse para a comunidade.

A área de estudo está no município de Petrolina/PE (Figura 1), que em conjunto com o município vizinho de Juazeiro/BA, forma o maior aglomerado urbano do semiárido. Esta escolha se deu devido a vários condicionantes favoráveis, como águas com salinidade de 82 a 13.000 mg/l de Sólidos Totais Dissolvidos (STD), alta densidade de ocupação rural, mais de 500 de poços cadastrados (CPRM, 2005).

Como a região de estudo possui contexto geológico cristalino, o armazenamento da água pluvial deve ser realizado através da injeção de água nas principais zonas de cisalhamento. Apesar da pequena espessura do solo desenvolvido na região semiárida, nas regiões de cisalhamento nota-se uma maior espessura das coberturas pedológicas, dificultando assim o mapeamento superficial das fraturas. Deste modo, a geofísica é uma ferramenta essencial para identificação destas zonas preferenciais de fluxo de água subterrânea. Dentre os métodos geofísicos usados em estudos hidrogeológicos, a eletrorresistividade mostra uma elevada eficiência no mapeamento de fraturas em aquíferos fissurais (RUBIN e HUBBART, 2005).

Normalmente em zonas fraturadas em rochas cristalinas, apresentam-se como regiões onde as resistividades tendem a ser mais baixas do que na mesma rocha quando não fraturada. Isto se deve ao fato que fraturamentos tendem a armazenar água e conter minerais argilosos produzidos pela ação da água e consequente alteração ocasionando menor resistividade nestas regiões (IPT 1994; GALLAS 1998, 2000).

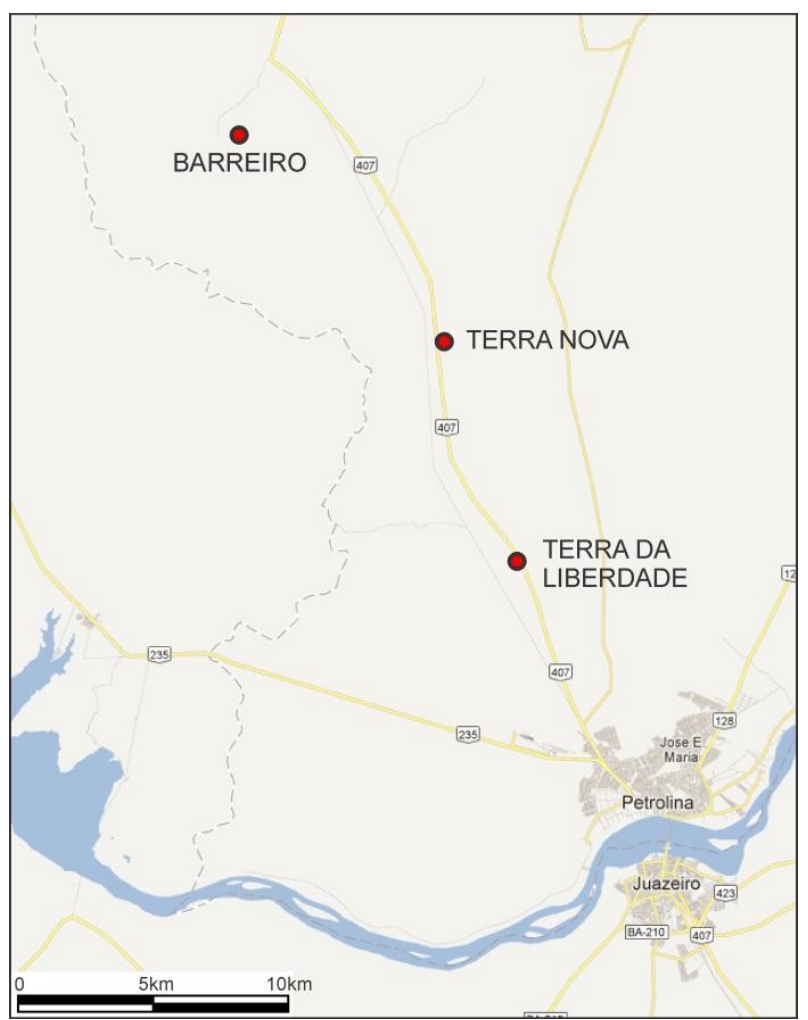

FIGURA 1: Localização das áreas investigadas no município de Petrolina/PE. 


\section{METODOLOGIA}

O método de eletrorresistividade baseia-se no estudo do potencial elétrico tanto dos campos elétricos naturais, existentes na crosta terrestre, como dos campos artificialmente provocados. A partir de medições no potencial elétrico na superfície pode-se determinar, no subsolo, a existência de corpos minerais e reconhecer estruturas geológicas (TELFORD et al, 1990).

Dentre os fatores mais importantes para a resistividade de uma rocha estão a quantidade de água e a salinidade da mesma. O aumento do valor desses fatores, teor de umidade e quantidade de sais dissolvidos, leva a uma diminuição dos valores de resistividade. Essa condição é que permite a imensa possibilidade de aplicação do método em estudos hidrogeológicos (TELFORD et al, 1990).

No caso de aquíferos cristalinos, a técnica do caminhamento elétrico é a mais adequada para identificar zonas de fraturamento. Essa técnica se baseia na análise e interpretação de um parâmetro físico, obtido a partir de medidas efetuadas na superfície do terreno, ao longo de uma seção, sua variação horizontal a uma ou mais profundidades investigadas (BRAGA, 2007). Pode-se posicionar, em superfície, a zona de anomalia condutora (associada a zonas de fraturas), bem como estimar 0 mergulho da estrutura identificada. Neste trabalho foram realizadas simulações numéricas para verificar quais os melhores arranjos de eletrodo a ser utilizados nas etapas de campo.

\section{Simulação numérica e Modelagem Direta}

A modelagem direta foi realizada no software RES2DMOD, versão 3.1. Este software calcula, por diferenças finitas ou elementos finitos, a pseudo-seção de resistividade elétrica aparente. Para isto, o usuário fornece um modelo de blocos retangulares, onde cada bloco tem seu parâmetro específico (o tamanho, a profundidade e a resistividade elétrica). Foram utilizados dois tipos de arranjo, dipolo-dipolo (DD) e o WennerSchlumberger (WS), variando o espaçamento entre os eletrodos (1, 2, 5 e 10 metros), com 36 eletrodos. Outro parâmetro definido foram os valores de resistividade do modelo, a rocha não alterada com 1000 Ohm.m, o solo com 200 Ohm.m e a fratura com 50 Ohm.m, estes valores foram baseados na geologia local da área de estudo, que é essencialmente rocha gnáissica e xistos (Figura 2).

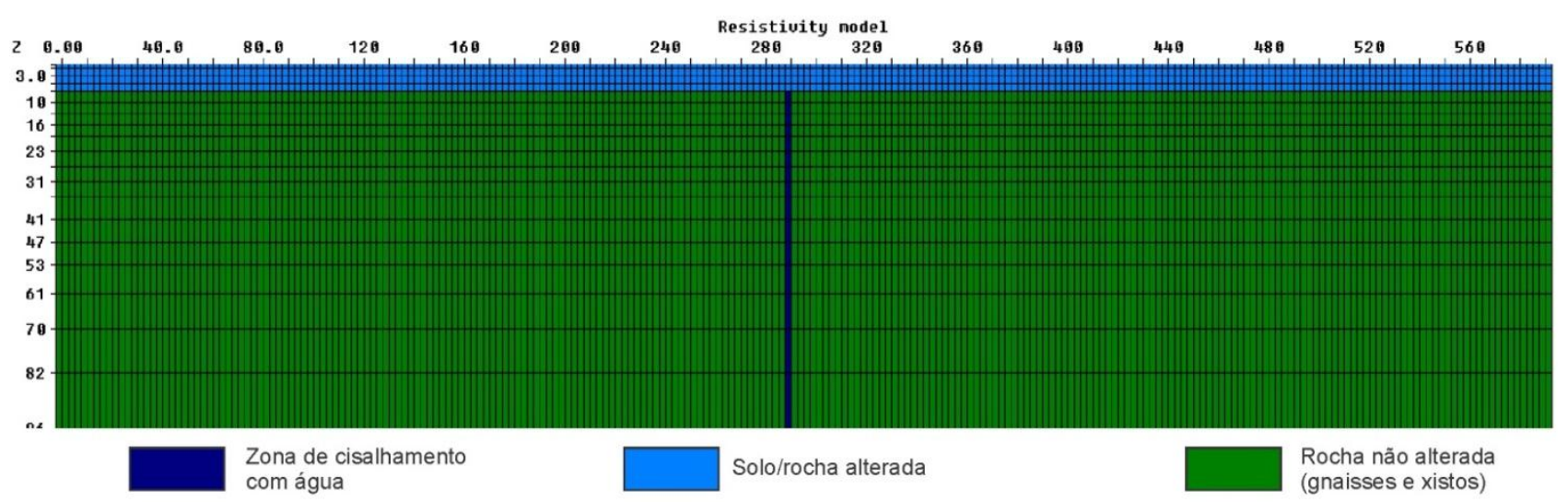

Figura 2: Modelo de blocos de resistividade elétrica elaborado no software RES2DMOD para simular uma zona de fraturamento em rochas gnáissicas cobertas por um horizonte raso de solo.

Os resultados da modelagem direta foram exportados para o formato de entrada do software de modelagem inversa RES2DINV, adicionado de um ruído gaussiano de $5 \%$. A interpretação quantitativa das simulações diretas tem o objetivo de verificar qual o melhor arranjo eletródico para identificar a zona de cisalhamento neste tipo de ambiente geológico. A Figura 3 mostra os resultados das inversões dos dados após a modelagem direta. Nota-se que em ambos os arranjos eletródicos possibilitam a identificação da zona de cisalhamento com boa precisão, deste modo estes dois arranjos foram usados em campo em função de sua maior resolução em superfície (DD) e maior razão sinal/ruído e profundidade de investigação (WS).

\section{Aquisição de Dados em Campo e Modelagem Inversa}

As aquisições de dados elétricos 2D foram desenvolvidas no período de janeiro a fevereiro de 2012 , com o objetivo de localizar as principais zonas de cisalhamento.

Foram investigadas três localidades dentro do município de Petrolina: o Assentamento Terra da Liberdade, a Comunidade Barreiro e a Comunidade Terra Nova. Essas localidades foram escolhidas em função da facilidade para a captação de água pluvial através de telhados próximos e da necessidade de água para abastecimento da comunidade local.

Neste trabalho foi utilizado o equipamento multicanal Syscal Pro 72 (Figura 4), com 36 eletrodos, usando-se 
os arranjos DD e WS com espaçamento de 10 metros, Os dados de campo foram modelados no software atingindo-se a profundidade média de 40 metros. RES2DINV.

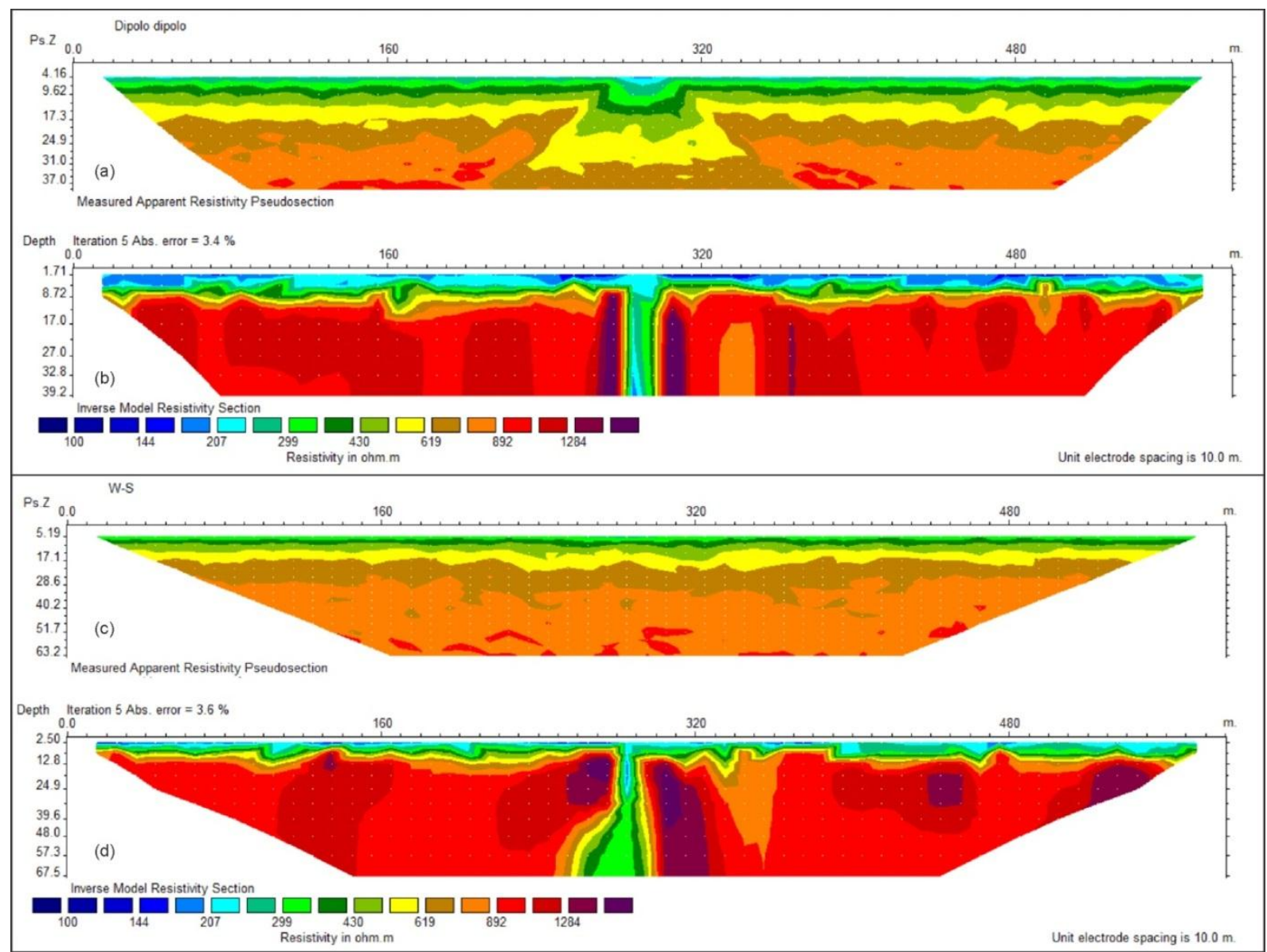

FIGURA 3: (a) Seção, de resistividade aparente, obtida por modelagem direta para arranjo $D D$. (b) modelo, de resistividade elétrica, obtido após modelagem inversa da seção "a". (c) Seção, de resistividade aparente, obtida por modelagem direta para arranjo WS. (d) modelo, de resistividade elétrica, obtido após modelagem inversa da seção "c".

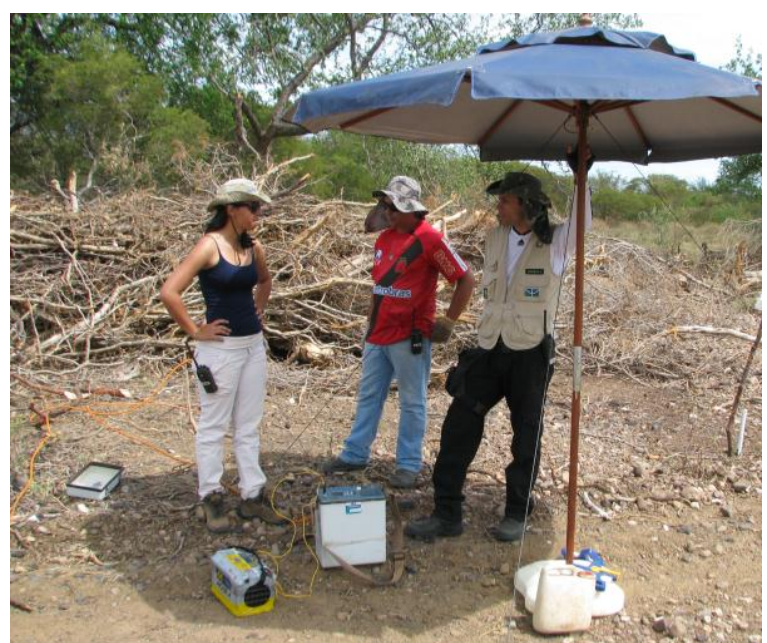

FIGURA 4: Foto evidencia a aquisição de dados de eletrorresistividade com o equipamento Syscal Pro 72.

\section{RESULTADOS}

Os resultados de eletrorresistividade mostrados neste trabalho possibilitam a localização de zonas de cisalhamento em locais de ocorrência de rochas cristalinas.

A Figura 5 mostra os resultados obtidos no Assentamento Terra da Liberdade. Ambos os resultados obtidos com os arranjos DD e WS evidenciam nos perfis, entre 270 e 300 metros, uma região de baixa resistividade $(<100$ Ohm.m). Esta região é interpretada como uma possível zona de fraturamento (PZF) ou um contato geológico entre duas unidades distintas. Esta interpretação é fundamentada na variação lateral de resistividade, uma vez que nos perfis, a partir de 265 metros, nota-se um aprofundamento do horizonte geoelétrico condutivo.

Os resultados de eletrorresistividade obtidos na Comunidade Terra Nova (Figura 6) mostram um embasamento rochoso mais raso que nas demais áreas. 
Para indicação de uma área para perfuração de poço de injeção de água foi necessário correlacionar as duas seções, uma vez que a seção obtida com o arranjo DD mostrar outras áreas favoráveis (Figura 6b). Nota-se que existe um aprofundamento do embasamento rochoso no modelo elétrico do arranjo WS (Figura 6d). Deste modo, recomenda-se a perfuração entre a posição de 90 e 105 metros do perfil (Figura 6).

De acordo com o modelo de resistividade elétrica da Comunidade Barreiro (Figura 7), obtido após a inversão com o arranjo DD (Figura 7b), foi possível verificar um padrão anômalo com resistividade de 376 Ohm.m, interpretado como PZF, entre a posição de 65 e 75 metros do perfil. Em ambos os arranjos (WS e DD) foi possível identificar um embasamento rochoso superior de baixa resistividade, porém a área demarcada como PZF foi definida analisando apenas o modelo gerado pelo arranjo DD, pois o modelo de resistividade elétrica com o arranjo WS não foi eficiente na identificação de uma PZF nesta região. Este local também foi indicado para perfuração de poço por ser mais favorável para o armazenamento de água pluvial, já que se encontra próximo a uma escola.

\section{DISCUSSÃO E CONCLUSÕES}

A eletrorresistividade é um método indireto de prospecção e de grande utilidade na busca e detecção de estruturas favoráveis para armazenamento de água. No nordeste este método será útil para o armazenamento de águas em época de chuva, e posterior utilização desta em épocas de estiagem.

Os resultados das aquisições de campo evidenciam principalmente a diferença entre a cobertura pedogenética e o topo do embasamento rochoso. Sugere-se a presença de fraturas através da forma do rebaixamento do embasamento rochoso, ou seja, nos locais onde existem pequenos vales interpreta-se como possíveis zonas de cisalhamento. Esta interpretação é fundamentada em princípios de intemperismo, uma vez que as fraturas aumentam a espessura do solo na região do semiárido.

Os poços serão locados nos locais indicados nas seções de eletrorresistividade e novas aquisições serão efetuadas durante as etapas de injeção de água ao longo das fraturas, com o objetivo de verificar possíveis padrões elétricos que possibilitem a reconstrução do comportamento hidráulico subterrâneo.

\section{AGRADECIMENTOS}

A FINEP pelo financiamento do projeto de pesquisa Hidrofrat, Subprojeto Recarfrat, através do Edital CTHIDRO 01/2010.

Ao Laboratório de Geofísica Aplicada (LGA/UnB) pela disponibilização dos equipamentos geofísicos.

\section{REFERÊNCIAS}

BRAGA, A.C.O. 2007. Módulo: Métodos Geoelétricos Aplicados nos Estudos de Captação e Contaminação das Águas Subterrâneas. Instituto de Geociências e Ciências Exatas, Unesp, Rio Claro/SP, 80p.

CPRM. 2005. Projeto cadastro de fontes de abastecimento por água subterrânea. Diagnóstico do Município de Petrolina. Relatório Final. 47p.

GALLAS, J.D.F. 1998. Eletrorresistividade aplicada à prospecção de água subterrânea em áreas de rochas cristalinas. In. WORKSHOP DE GEOFÍSICA APLICADA, II, 1998, Rio Claro. Anais..., Rio Claro 1998, CDROM, Arquivo Wga09.RTF.

RUBIN, Y. e HUBBARD, S.S. 2005. Hidrogeophysics. Water Science and Technology Library, Volume 50, Springer, Netherlands, 527p.

TELFORD WM, GELDART LP e SHERIFF RE. 1990. Applied geophysics. Segunda Edição. Cambridge: Cambridge University Press, 770 p. 


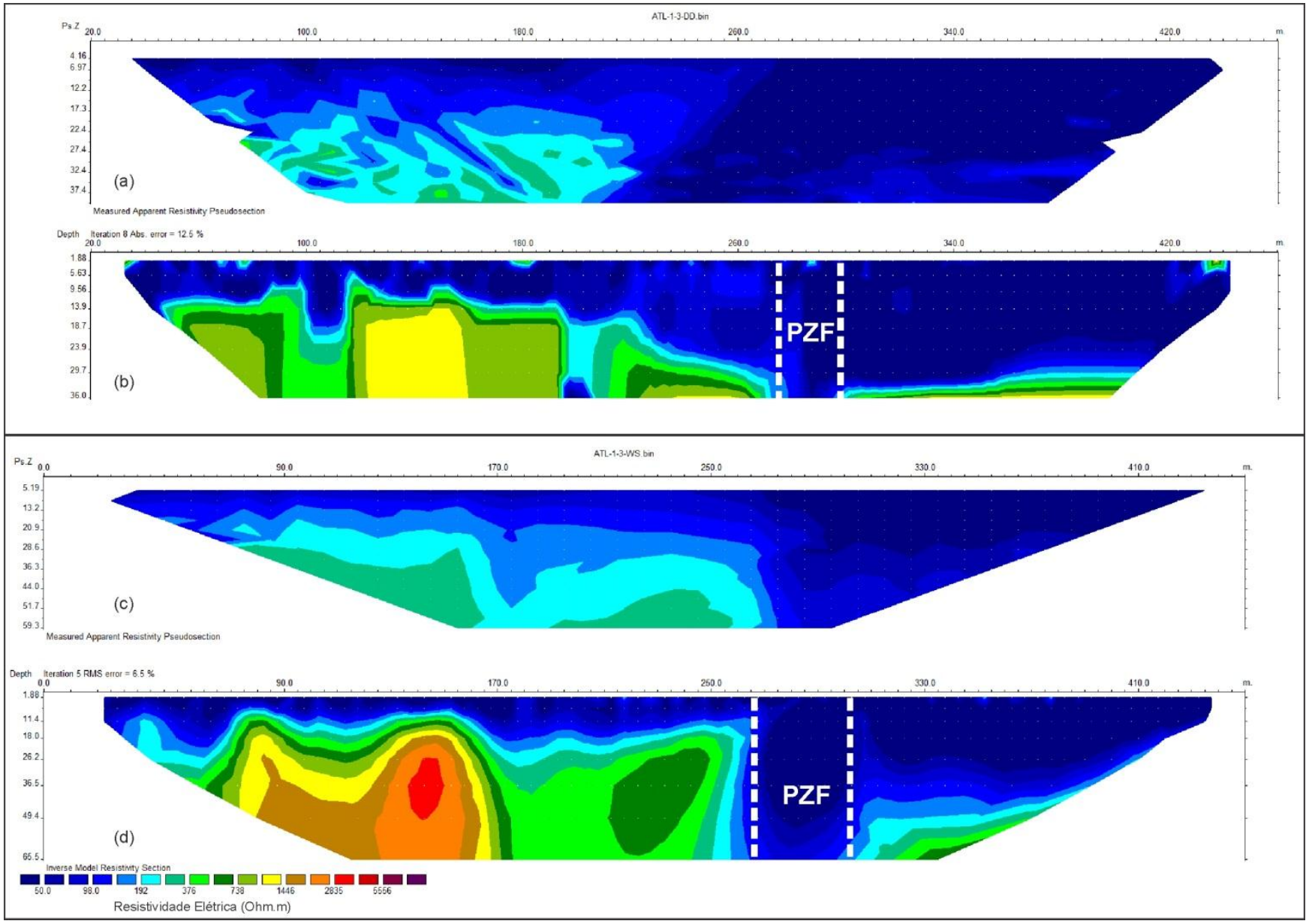

Figura 5: Seções de resistividade, obtidas no Assentamento Terra da Liberdade. (a) Pseudo-seção de resistividade aparente dos dados de campo com o arranjo dipolo-dipolo.(b) Modelo de resistividade elétrica obtido após a inversão com o arranjo dipolo-dipolo.(c) Pseudo-seção de resistividade aparente dos dados de campo com o arranjo Wenner-Schlumberger. (d) Modelo de resistividade elétrica obtido após a inversão com o arranjo Wenner-Schlumberger. As possíveis zonas de falhamentos são indicadas (PZF). 


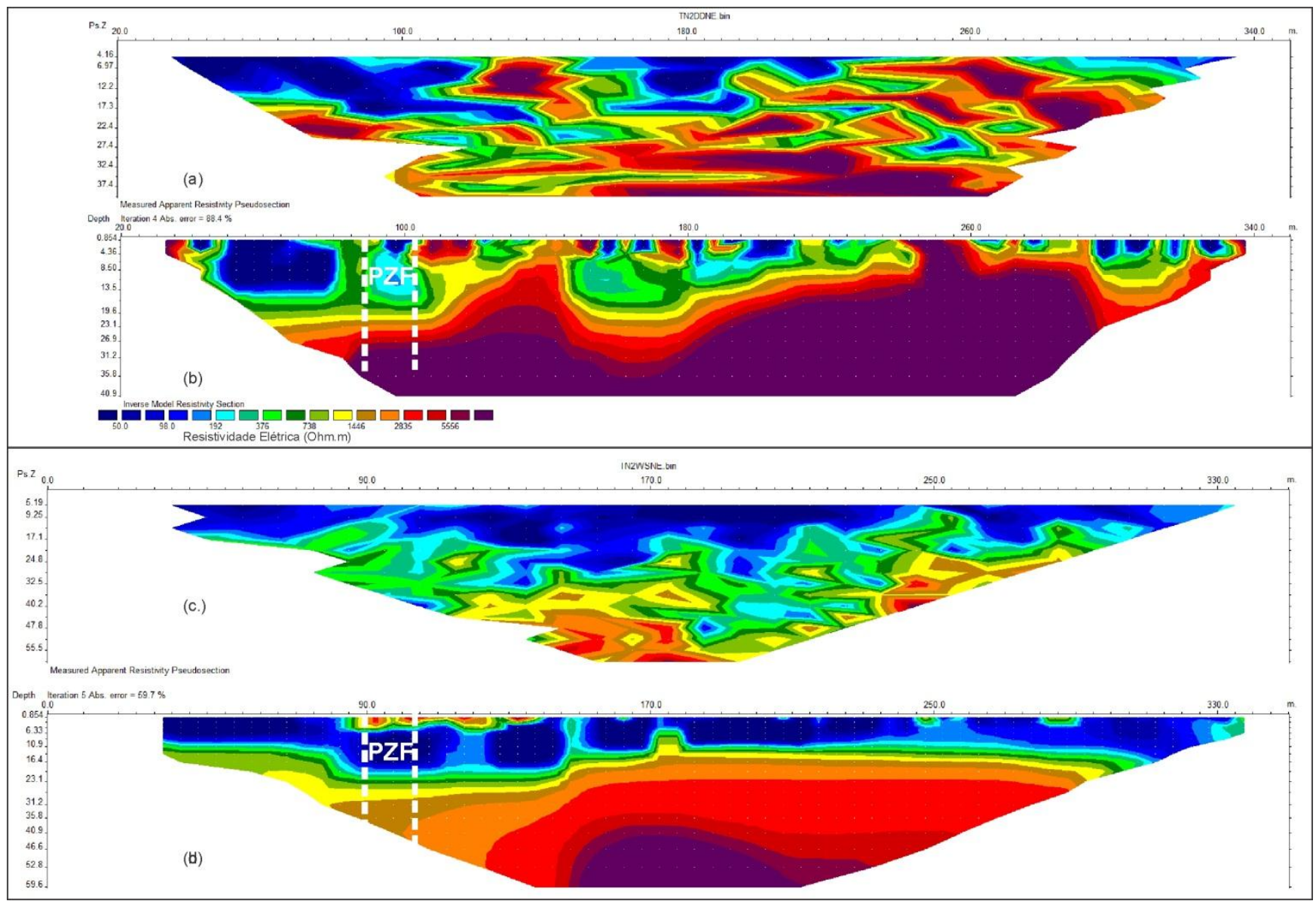

Figura 6: Seções de resistividade, obtidas na comunidade Terra Nova. (a) Pseudo-seção de resistividade aparente dos dados de campo com o arranjo dipolo-dipolo.(b) Modelo de resistividade elétrica obtido após a inversão com o arranjo dipolo-dipolo.(c) Pseudo-seção de resistividade aparente dos dados de campo com o arranjo Wenner-Schlumberger. (d) Modelo de resistividade elétrica obtido após a inversão com o arranjo Wenner-Schlumberger. As possíveis zonas de falhamentos são indicadas (PZF). 


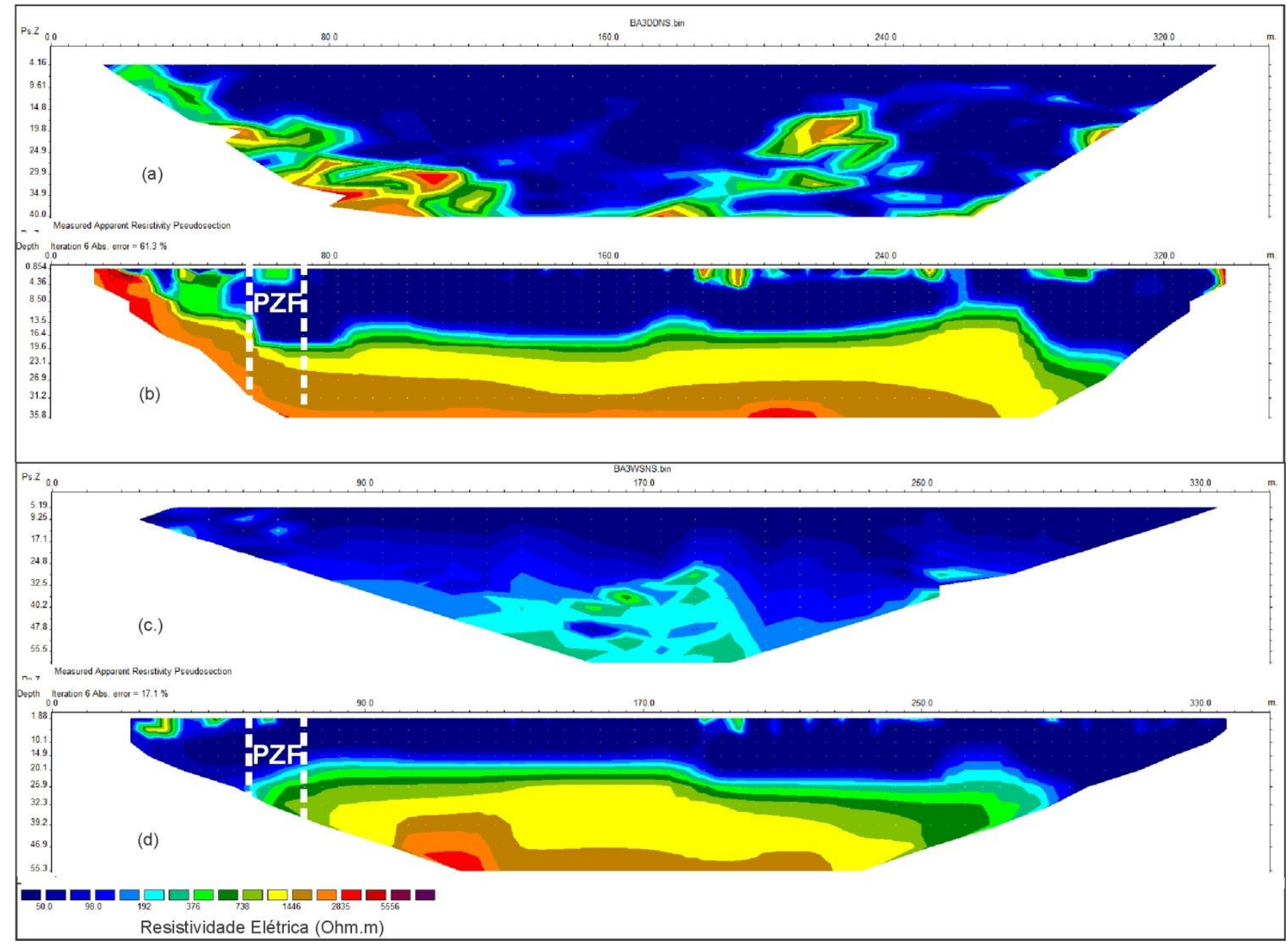

Figura 7: Seções de resistividade, obtidas na comunidade Barreiro. (a) Pseudo-seção de resistividade aparente dos dados de campo com o arranjo dipolo-dipolo.(b) Modelo de resistividade elétrica obtido após a inversão com o arranjo dipolodipolo.(c) Pseudo-seção de resistividade aparente dos dados de campo com o arranjo Wenner-Schlumberger. (d) Modelo de resistividade elétrica obtido após a inversão com o arranjo Wenner-Schlumberger. As possíveis zonas de falhamentos são indicadas (PZF). 